\title{
Design and Implementation of Ubiquitous Fraction App for Fraction Learning in Authentic Contexts
}

\author{
Uun Hariyanti ${ }^{*}$ and $\mathrm{Wu}-$ Yuin Hwang \\ Graduate Institute of Network Learning Technology, National Central University, Taiwan
}

\begin{abstract}
An amount of research had identified some difficulties that were faced by students when they learned fractions, which is known as one of the essential parts of mathematics. On the other hand, designing mathematics learning in authentic contexts could beneficial to students, such as increase their motivation and collaboration. Thus, we develop a Ubiquitous App, namely Ubiquitous Fraction (U-Fraction), to facilitate fraction learning in authentic contexts by providing useful features. This study was designed to investigate the relationship among three categories of learning variables, including quantity of learning, quality of learning, and learning achievement, and to identify sequences of interactions when students use U-Fraction in authentic contexts. There were 27 five-grade students participated in this study. The data were analyzed using parametric and nonparametric tests, including pair t-test, correlation, lag sequential, and descriptive analysis. In summary, four important findings are highlighted in this study. First, the pair t-test result showed that there was a significant difference in students' acquisition of fraction knowledge before and after the learning process. Second, the importance of correlation analysis results indicated that students' learning achievement would depend more on their quality of learning rather than their quantity of tasks that had been solved by them. Third, results from sequential analysis indicated that students intended to do the next steps after they finished the previous step in fraction learning with authentic contexts. Fourth, a questionnaire, which is Sustainable and Scalable Authentic Learning (SSAL), results indicated that most students agree that learning with U-Fraction in authentic contexts could have a positive impact on the ability to collaborate with others. Finally, these results indicate that authentic learning supported by the Ubiquitous App can increase not only students' achievements and engagements but also influence their positive attitude toward learning activities.
\end{abstract}

Keywords: authentic contexts; ubiquitous fraction; authentic learning; peer sharing; peer assessment

\section{Introduction}

Nowadays, designing learning anytime and anywhere has become more prevalent in educational design. Such learning can give students a number of benefits to increase their experience, learning ability, and engagement. With the rapid development of information and communication technologies, mobile devices become popular in ubiquitous learning that is easily conducted anytime and anywhere because those are small, lightweight, and convenient to carry around for a long period of time (Boticki et al. 2013, Kulkulska-Hulme and Viberg, 2018). Because of these advantages, mobile devices had been widely used in various fields of mathematics learning, such as fractions learning (Hwang et al. 2019b). Regarding fractions learning, an amount of research had identified some difficulties that were faced by students when they learned fractions, including the use of notations to represent fractions (Brizuela, 2006) and the use of fraction procedures to operate the numerators and denominators (Jordan et al. 2017). In order to solve these problems, some researchers conducted studies in fraction learning by employing graphical fraction representations, interactive learning tools, and meaningful learning tasks that make students relate to real-world applications or authentic contexts (Kong and Kwok, 2003, Hwang et al. 2015). The aforementioned studies indicate that employing graphical fraction representations, interactive learning tools, and meaningful learning tasks gave beneficial to fraction learning, decreased students' difficulties, and increased students' motivation. However, there are only a few studies that focused on providing fraction learning with interactive learning tools that can help students to learn from authentic contexts in which is a physical environment that reflects the way of knowledge will be used in the real world. Thus, we develop a 
Ubiquitous Fraction App (U-Fraction) to facilitate fraction learning with authentic contextual support by providing useful features, such as authentic tasks and making multiple representations. These representations include fraction representation in words, symbolical, and visual (graphical and authentic picture).

Considering the aforementioned features, we need to pay attention to how to design the features of the ubiquitous app that can affect students' learning process. The design of features not only considers essential contents but also considers the learning sequences when students are doing transfer knowledge in their learning because these can influence the cognitive process that will be happened ( $\mathrm{Wu}$ et al. 2016). Therefore, understanding the appropriate sequential structure of learning interaction employing the ubiquitous app is a critical issue that should be clarified. However, there are only a few studies which have investigated the relation of learning sequences and cognitive process, especially in ubiquitous learning design.

Understanding the sequential structure of interaction in learning needs to use an appropriate method. It cannot be analyzed by interviews or questionnaire methods, but we can use an observation method that can investigate the chronology of the students' activities (Pohl et al. 2012). According to the observation method, log files can be employed to capture interaction sequences in an easy way. Besides the observation of sequential learning interaction, relating the learning activities with students' perceptions also becomes an important issue. Regarding an efficient learning method, students' perception can govern whether learning becomes a promising method that can be implemented in an educational setting.

The goals of this study are to investigate how the use of U-Fraction and authentic contexts could help students' learning fractions and to describe the learning sequence when students used the U-Fraction in authentic contexts with the designed learning cycle. Furthermore, the students' perceptions toward the fraction learning with UFraction in authentic contexts are also analyzed to know the effectiveness of the learning.

\section{Related Works}

\section{Authentic Task in Ubiquitous App}

Designing an educational app based on tasks need to pay attention to various factors, e.g., students' cognitive development, interactive activities, and task complexity. It is followed by the fact that the design of an app will affect users' cognitive processes (Belk et al. 2017, Wang et al. 2020). Furthermore, Reychav and Wu (2016) describe how various complexity of cognitive tasks become an important role in developing an interactive mobile app. They argue that the balance between the interface design of systems and the complexity levels of cognitive tasks is needed to achieve the desired outcomes. This result is in harmony with Van Gog, Kester, and Paas (2011) mentioning that complicated learning tasks can increase cognitive load so that it will decrease task performance as well. Thus, providing appropriate tasks for students based on their cognitive development stage becomes a critical issue in designing educational apps.

According to the cognitive development of elementary students, the use of authentic contexts in students' tasks can promote a better learning environment (Hwang et al. 2019a, 2019b). In addition, the use of authentic contexts can assist students in transferring useful knowledge to their real-world activities and encourage activestudents centered learning (Herrington et al. 2014, Volk et al. 2017). However, implementing authentic contexts to promote an authentic learning environment can be criticized if it cannot satisfy some essential characteristics. Newmann and Wehlage (1993) and Herrington and Oliver (2000) had highlighted four essential characteristics of the authentic environment, such as providing authentic contexts, involving authentic activities, sharing learning experiences, and offering an authentic assessment. In order to satisfy these characteristics, advanced learning technologies, such as ubiquitous apps, can be implemented in the learning to provide students with an authentic learning environment (Shadiev et al. 2018). 
In the previous study, called U-Fraction, had been implied in the five-grade elementary school. The results indicate that students' achievements had positively improved as well as their behavior engagement in the classroom (Hwang et al. 2019b). However, the study lack consideration of how to navigate students to find an appropriate authentic context in their tasks. Hence, it is needed to provide students with an app possessing a navigation tool to guide students while exploring their surroundings.

Based on the above mentioned, designing authentic tasks for elementary students need to rely on authentic contexts in which are a physical environment that reflects the way knowledge will be used in the real world. Besides, authentic activities that mean activities done in authentic contexts, sharing experience also becomes an important part of enabling students to works with others to build their knowledge and to help them overcome learning difficulties. Regarding the use of a ubiquitous app, the features in the app should be well designed so the interactions occurring among students, authentic tasks, and authentic contexts with the app support can promote a meaningful learning behavior.

\section{Multiple Representations}

Representation is a common way in the delivery of information to the user while using an app. On the other hand, representation also regularly used in mathematics. There are five categories of representations used in mathematics (Nakahara, 2008), which are symbolical representation, linguistic representation, illustrative representation, and manipulative representation. The application of multiple representations in mathematical learning proved that it could help the students achieve the mathematical concept process in problem-solving more deeply (Debellis and Goldin, 2006). A study conducted by Spiro, Feltovich, Jacobson, and Coulson (1992) also revealed that delivering information by multimedia representation can make students easier to apply the knowledge and skills they already have to new situations because each representation has a unique and different view. Moreover, another study conducted by Kara and Incikabi (2018) also proved that students learning achievement in fraction operation are higher when using the different representation, such as numbers, number lines, text-explanations, and pictures. In this study, multiple representations were employed used to lead students to explore and verify the fraction application in real-world situations so that students in elementary school can understand fraction concepts more deeply. We focused on the use of fractions representation in words, symbolical, and visual (graphical and authentic picture) that were designed in students' authentic tasks.

\section{Sequence Analysis}

Understanding the users' interaction while interacting with educational apps is useful to know how the interaction occurs between users and apps. One common method to analyze user interaction with particular systems is the analysis of sequences that are commonly used in human-computer interaction research (Radinsky et al. 2013). Regarding the use of log files data, lag-sequential analysis (LSA) is an approach in sequence analysis that can examine various of repeated events in sequence data (Pohl et al. 2016). For example, Chung and Baker (2003) applied LSA based on logged user-interface events to examine the problem-solving process in an online learning environment. In the present study, LSA is used to understand whether the learning steps are correlated with each other in sequences during the authentic learning process.

\section{Ubiquitous Fraction App}

A Ubiquitous Fraction App (U-Fraction) is a tablet-based application powered by Android technology, openCV Camera, advanced whiteboard, GPS, and Google Maps to support students in authentic fraction learning. In order to guide the students when they try to solve an authentic fraction problem, we designed authentic tasks in the app that provide learning guidance. The learning guidance consists of seven steps (see Figure 1.) that are choosing the location-based fraction problem (CL), understanding problem (UP), navigating to the location 
(NL), problem-solving by exploration (SPE), describing work (DW), describing location (DL), and confirmation (C).

In the first step, the students must choose the nearest location of the location-based fraction problem based on their position in Google Maps. After they choose a location-based fraction problem, the system will bring the students to the second step, understanding problem. After that, the system will bring the students to the third step, navigating to the location. In this situation, a google map was provided to guide the students to reach a chosen location-based authentic problem.

In the fourth step, an advanced whiteboard is provided to help the students solve authentic problems. The students need to explore their surroundings to solve the problem. They need to find the object that has a rectangle or circular shape by using the OpenCV algorithm for image recognition. Students use a camera of a mobile device to capture the image of authentic contexts surrounding them, and the App can show the recognition result, such as a rectangle or circle, to create fraction representation. Then, students need to draw a fraction representation in a bar or pie form needed to complete their records. Moreover, they need to write some explanations in text and also a mathematical symbol to explain more about the fraction representation that had been made by them.

Besides the authentic contexts assignments, the U-Fraction also provides peer sharing and peer assessment mechanisms. Regarding the utilization of Google Maps to build a location-based fraction problem, the recorded location and the learning record will be used in location-based peer sharing. In location-based peer sharing, the students can confirm other students' records by coming close to the exact fraction learning record location. This function also uses the GPS function to locate the student's position before the system shows the closest other students learning records using Google Maps. After the system shows the other students learning records in Google Maps, students can choose and come close to those records to make a confirmation and do the peer assessment. 


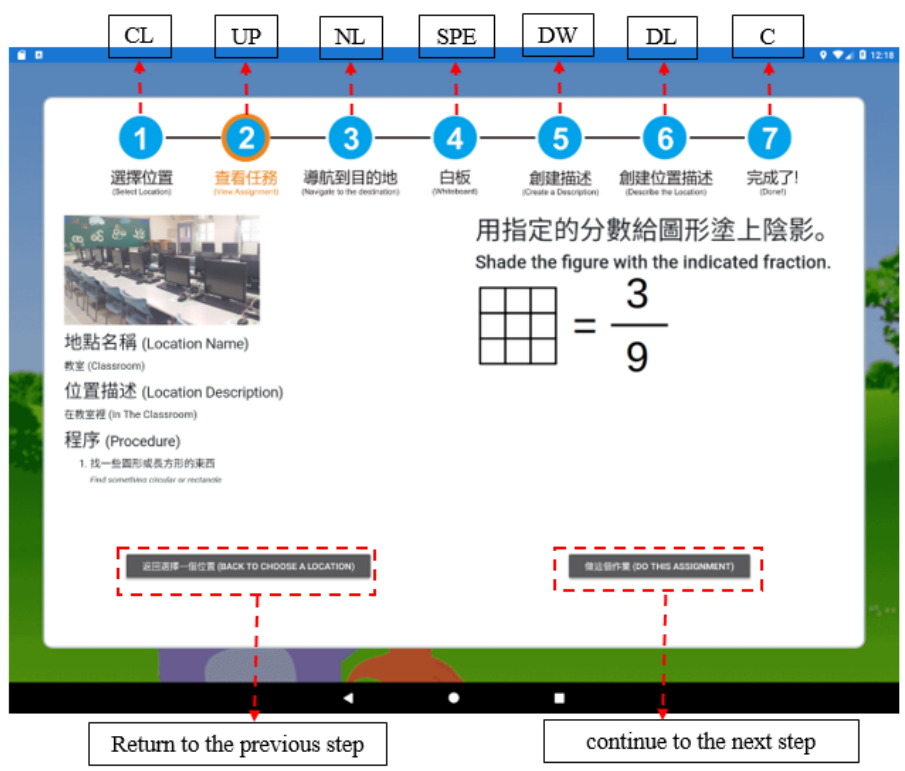

Figure 1 U-Fraction with seven steps for learning guidance: choosing the location-based fraction problem $(C L)$, understanding problem (UP), navigating to the location (NL), problem-solving by exploration (SPE), describing work $(D W)$, describing location $(D L)$, and confirmation $(C)$.

\section{Methods}

This study was conducted in Luzhou primary school, Taiwan. The learning activities that were done outside the classroom would be designed based on tasks in U-Fraction. The tasks are called authentic tasks that engaged students to learn in authentic contexts.

\section{Instructional Design}

Applying some mathematical knowledge, e.g., fractions concepts, in authentic contexts may give some positive effects for primary students. This regards the cognitive development theory (Wadsworth, 1996), known as Piaged' theory, which mentioned that students in primary schools need to think logically through manipulating concrete objects. Thus, in this study, a fraction learning following particular learning steps supported by UFraction was designed. The learning was designed based on authentic tasks that consist of three essential fraction topics, i.e., concepts of fraction, concepts of simplification, concepts of addition and subtraction.

The learning aims to understand the fraction concepts and to apply the concepts in authentic contexts. Regarding these aims, students need to explore their surroundings to find a fraction phenomenon related to a particular topic. Thus, this is the reason for using U-Fraction in this learning method. Besides that, students could widen their understanding of fraction concepts by giving a meaningful explanation in their tasks and looking at the other's work.

In the learning activities, we provide a tablet for each student, so they can explore their surroundings and move to different places based on their own. Students can collaborate with others to find a particular fraction phenomenon by providing a sharing mechanism in the app. This sharing mechanism was called location-based peer sharing, which enables a student to see the other's work. 


\section{Participants and Research Procedure}

A total of 27 five-grade students participated in this study. Pre-tests and post-tests were applied in this study. Both tests were similar (not same) and consisted of 10 fraction problems, including understanding fraction (3 problems), fraction representation (3 problems), and problem-solving (4 problems).

In the first week, students were given a pre-test that was done in 40 minutes. After that, students were trained to use U-Fraction for 40 minutes. In the next four weeks, students learned fractions using U-Fraction in authentic contexts. These learning periods were divided into two sections based on where the learning was done. The first section was done in the classroom, and the second section was done outside the classroom. In each section, students had to solve fraction tasks in authentic contexts and done peer assessment. After four weeks of learning periods, students were given a post-test and completed the designed questionnaire, SSAL questionnaire. One week later, some students were chosen to be interviewed. The detailed research procedure was illustrated in Figure 2.

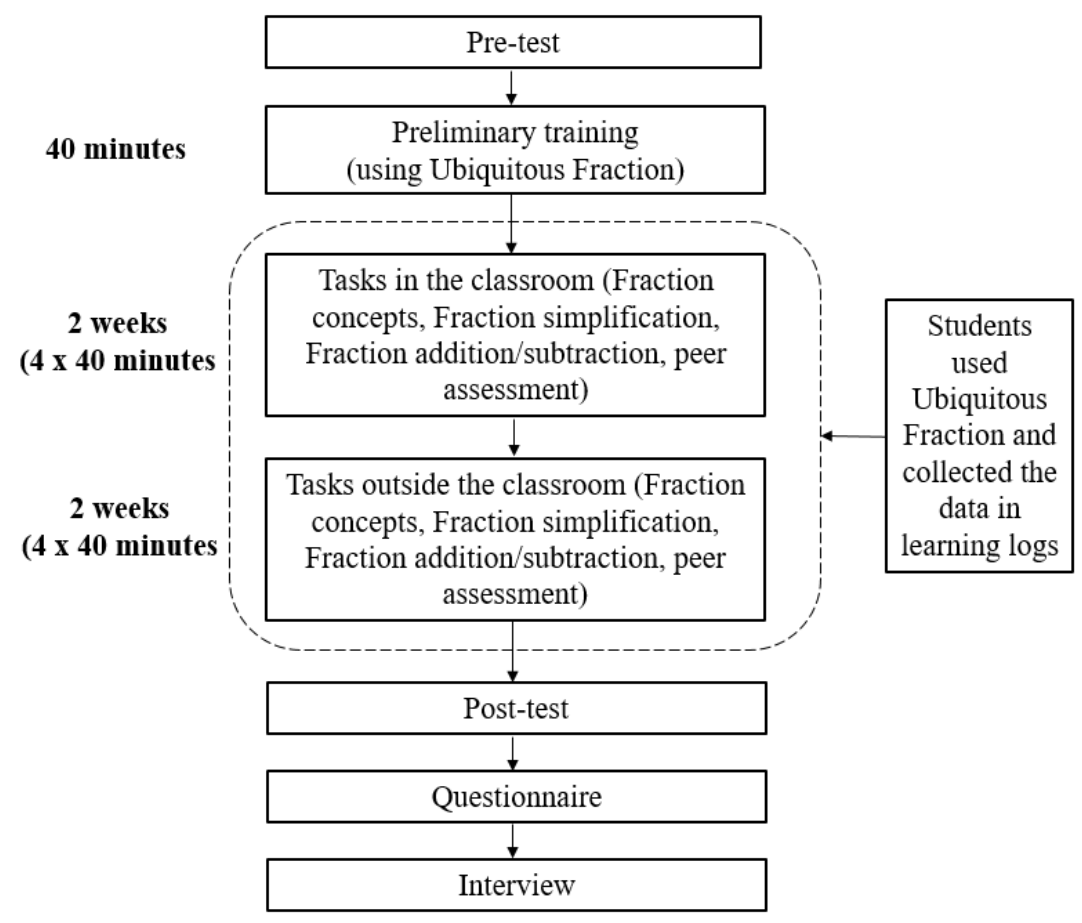

Figure 2 Research procedure.

\section{Research Variables}

According to the learning design, we collected students' research variables and divided these into three categories, including quantity of learning, quality of learning, and learning achievement. These three categories are represented in Table 1. 
Table 1 Research variables.

\begin{tabular}{ll}
\hline Variables & Description \\
\hline Quantity of learning & \\
\hline Tasks & Quantity of tasks that had been solved \\
\hline Annotations & Quantity of annotations that had been made \\
\hline Quality of learning & \\
\hline Peer assessment & Score from peer assessment \\
\hline Teacher assessment & Score from teacher assessment \\
\hline Learning Achievement & \\
\hline Post-test & Score of post-test \\
\hline
\end{tabular}

\section{Sustainable and Scalable Authentic Learning (SSAL) Questionnaire}

A questionnaire, called Sustainable and Scalable Authentic Learning (SSAL), was applied to examine students' perceptions toward the learning model. The SSAL questionnaire consisted of six latent variables that were designed to develop the three-dimension models. These dimensions are grouped according to the following trends: the first dimension consists of one variable construct called learning by applying (LA); the second dimension consists of two variable constructs called healthy learning (HL) and collaborative learning (CL); and the third dimension consists of three variable constructs called creativity $(\mathrm{Cr})$, sustainability $(\mathrm{Su})$ and Scalability (Sc). In order to carry out the six variables, there are 12 items that represent each variable, i.e., LA (LA1 and LA2), HL (HL1 and HL2), CoL (CoL1 and CoL2), Cr (Cr1 and Cr2), Su (Su1 and Su2), and Sc (Sc1, Sc2, and $\mathrm{Sc} 3)$.

The evaluation of the reliability of each item in the SSAL questionnaire was carried out by the assessment of indicator loadings. Loadings of each item are above 0.708 indicated that the construct has acceptable item reliability (Hair et al. 2019). Furthermore, Cronbach's alpha and composite reliability held the value above 0.70 and between 0.60 and 0.95 . Likewise, those values confirmed the internal consistency reliability exist in each construct (Hair et al. 2019). Furthermore, the convergent validity of each construct was addressed acceptable indicated by the AVE value was equal or higher than 0.05 for all items on each construct (Fornell and Larcker, 1981, Hair et al. 2019). In other words, the SSAL questionnaire is valid and reliable enough to be used as an analysis instrument.

\section{Results}

\section{Analysis of Knowledge Acquisition}

We used pair t-test analysis to know the difference between students' prior knowledge (pre-test) and their learning achievement (post-test). According to the pair t-test result, the mean value improved from 37.85 (SD = $15.92)$ to 43.37 ( $\mathrm{SD}=16.95)$, which indicate that there was significant difference $(\mathrm{t}(26)=2.09, \mathrm{p}=.046)$ in students' acquisition of fraction knowledge, before and after the learning process.

\section{Correlation among Quantity of Learning, Quality of Learning and Learning Achievement}

The Pearson correlation test (Table 2) revealed that the quantity of annotations had positive correlation with quantity of tasks $(r=.579, \mathrm{p}<0.1)$, peer assessment $(\mathrm{r}=.715, \mathrm{p}<0.1)$, teacher assessment $(\mathrm{r}=.759, \mathrm{p}<0.1)$ and post-test $(\mathrm{r}=.621, \mathrm{p}<0.1)$. It means that annotations made by students were useful to understand the fraction concepts and improved their knowledge. Furthermore, the interview result indicates how annotation had an important role in their learning. According to the interview, students stated that annotations were important 
because the notes that had been made were helpful while they wanted to review their works. On the other hand, the notes also helped students when they wanted to review others' works. By doing so, they could compare their works with others and improve their understandings.

Table 2 also shows that the quality of learning, both from peer assessment scores $(r=.426, p<0.1)$ and teacher scores $(r=.664, p<0.1)$, had positive correlation with learning achievement (post-test). However, the quantity of tasks had not correlated with the post-test. In other words, these results implied that students' learning achievement would depend more on their quality of learning rather than their quantity of tasks that had been solved by them.

Table 2 Pearson correlation coefficient among quantity of learning, quality of learning and learning achievement. Note: **Correlation is significant at .01 level (2-tailed)

\begin{tabular}{llllll}
\hline & 1 & 2 & 3 & 4 & 5 \\
\hline Quantity of learning & & & & - & - \\
\hline Tasks & 1 & - & - & - & - \\
\hline Annotations & $.579^{* *}$ & 1 & - & & - \\
\hline Quality of learning & & & & \\
\hline Peer assessment & $.662^{* *}$ & $.715^{* *}$ & 1 & - & - \\
\hline Teacher assessment & - & $.759^{* *}$ & - & & \\
\hline Learning achievement & & & & $.664^{* *}$ & 1 \\
\hline Post-test & - & $.621^{* *}$ & $.426^{* *}$ & \\
\hline
\end{tabular}

\section{Sequential Analysis}

A lag sequential analysis (LSA) was used to analyze the students' behaviors when they solve fraction problems in authentic contexts using a Ubiquitous Fraction App. First, we extract students' activity when they use the app from the log files data. Regarding fraction learning activities in authentic contexts, the app provided students with seven learning steps that should be followed, but it did not rule out the possibility that students would repeat some steps because the system allowed it.

At first, we show the frequencies of code behaviors during authentic learning activities with the app in four different authentic locations. In total, there are 3599 activities done in four different authentic locations during the activities outside the classroom. The result shows that around the class $(n=2005)$ is the most favorite location to do the authentic tasks followed by the hall $(\mathrm{n}=824)$, playground $(\mathrm{n}=531)$, and sports yard $(\mathrm{n}=$ 237). This is because students could more readily found the fraction objects around the classroom (e.g., the wall with a tile pattern, floor, windows) than the other location.

The most common activity from four different authentic locations is CL $(\mathrm{n}=708,20 \%)$ followed by UP $(\mathrm{n}=$ $626,17 \%)$, SPE $(\mathrm{n}=572,16 \%), \mathrm{NL}(\mathrm{n}=499,14 \%), \mathrm{DW}(\mathrm{n}=463,13 \%), \mathrm{DL}(396,11 \%)$, and $\mathrm{C}(\mathrm{n}=335,9 \%)$ (see Table 3).

A chi-square test confirmed a significant relation between the rows and columns in transitional frequency matrix, $\square 2=9901.9372, \mathrm{df}=36, \mathrm{p}<.001$. The most probable cases are those where one step follows the next step (e.g., $\mathrm{CL} \rightarrow \mathrm{UP} \rightarrow \mathrm{NL} \rightarrow \mathrm{SPE} \rightarrow \mathrm{DW} \rightarrow \mathrm{DL} \rightarrow \mathrm{C} \rightarrow \mathrm{CL}$ ). This is indicated that students tend to do the next activity after finished the previous activity.

Finally, the sequences of activities reach significance levels depending on the computation of $\mathrm{z}$-values (that is > $\mathrm{z}$ 1.96) and Yule's $\mathrm{Q}$ (that is $>\mathrm{Q}$ 0.30) (Bakeman and Gottman, 1997). The results, in Table 4, indicate that the following sequences were significant: $\mathrm{CL} \rightarrow \mathrm{UP}(\mathrm{z}=50.65, \mathrm{Q}=0.993), \mathrm{UP} \rightarrow \mathrm{NL}(\mathrm{z}=49.78, \mathrm{Q}=0.996)$, 
$\mathrm{NL} \rightarrow \mathrm{SPE}(\mathrm{z}=48.46, \mathrm{Q}=0.990), \mathrm{SPE} \rightarrow \mathrm{DW}(\mathrm{z}=52.48, \mathrm{Q}=0.999), \mathrm{DW} \rightarrow \mathrm{DL}(\mathrm{z}=51.72, \mathrm{Q}=0.997), \mathrm{DL} \rightarrow \mathrm{C}(\mathrm{z}$ $=54.48, \mathrm{Q}=1.000), \mathrm{C} \rightarrow \mathrm{CL}(\mathrm{z}=38.30, \mathrm{Q}=0.997)$.

Table 3 Frequencies of Activities

\begin{tabular}{lllllllll}
\hline & CL & UP & NL & SPE & DW & DL & C & Total \\
\hline CL & 96 & 581 & 14 & 5 & 2 & 10 & 0 & 708 \\
\hline UP & 120 & 0 & 478 & 25 & 0 & 2 & 1 & 626 \\
\hline NL & 32 & 18 & 2 & 447 & 0 & 0 & 0 & 499 \\
\hline SPE & 101 & 3 & 0 & 3 & 459 & 6 & 0 & 572 \\
\hline DL & 8 & 1 & 0 & 78 & 0 & 376 & 0 & 463 \\
\hline C & 19 & 22 & 4 & 14 & 2 & 1 & 334 & 396 \\
\hline Total & 731 & 1 & 1 & 1 & 0 & 1 & 0 & 335 \\
\hline
\end{tabular}

Note: Step1: Choosing Location (CL), Step2: Understanding Problem (UP), Step3: Navigate to Location (NL), Step4: Solving Problem by Exploration (SPE), Step5: Describing Work (DW), Step6: Describing Location (DL), Step7: Confirmation (C)

Table 4 Adjusted residual (z-values) between the different learning steps

\begin{tabular}{llllllll}
\hline & CL & UP & NL & SPE & DW & DL & C \\
\hline CL & -4.55 & 50.65 & -10.21 & -12.35 & -11.16 & -9.10 & -9.51 \\
\hline UP & -0.33 & -12.63 & 49.78 & -8.97 & -10.58 & -9.40 & -8.67 \\
\hline NL & -8.02 & -8.75 & -9.38 & 48.46 & -9.25 & -8.46 & -7.71 \\
\hline SPE & -1.30 & -11.61 & -10.46 & -10.97 & 52.48 & -8.30 & -8.36 \\
\hline DW & -10.39 & -10.45 & -9.25 & 0.58 & -8.86 & 51.72 & -7.39 \\
\hline DL & -7.88 & -6.59 & -7.85 & -7.14 & -7.79 & -7.25 & 54.48 \\
\hline C & 38.29 & -8.67 & -7.55 & -8.21 & -7.39 & -6.57 & -6.16 \\
\hline
\end{tabular}

From the result of the analysis, we get the behavior transition of fraction learning in authentic contexts using the U-Fraction that is illustrated in Figure 3.

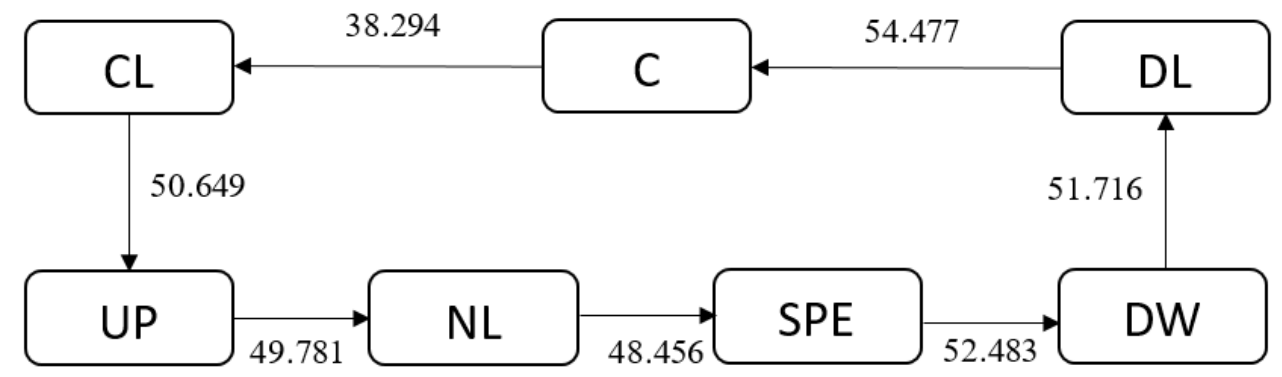

Figure 3 The behavior transition of fraction learning in authentic contexts using Ubiquitous Fraction App

\section{Students' perception toward the Fraction Learning in Authentic Contexts}

To find out the students' perception toward the Fraction Learning in Authentic Contexts, we used an SSAL Questionnaire composed of five-points Likert scales (from 1 means "very disagree" to 5 means "very agree"). Concerning the means and standard deviations values of each item in the questionnaire, the result indicates that 
two items (L2 and CL1) had the highest means (M>4). In addition, the order of the dimensions according to the means values is CL $(\mathrm{M}=4)$, LA $(\mathrm{M}=3.98), \mathrm{Sc}(\mathrm{M}=3.8), \mathrm{Su}(\mathrm{M}=3.79), \mathrm{Cr}(\mathrm{M}=3.74)$ and $\mathrm{HL}(3.53)$.

Table 5 Questionnaire result of fraction learning in authentic contexts using U-Fraction

\begin{tabular}{|c|c|c|c|c|}
\hline $\begin{array}{l}\text { Latent } \\
\text { variables }\end{array}$ & Items & Statements & M & SD \\
\hline \multirow[t]{2}{*}{ LA } & L1 & $\begin{array}{l}\text { I relate the concepts of fractions with my surroundings using U- } \\
\text { Fraction app. }\end{array}$ & 3.81 & 1.178 \\
\hline & L2 & $\begin{array}{l}\text { Using U-Fraction app can help me to identify fraction objects in my } \\
\text { surroundings. }\end{array}$ & 4.15 & .989 \\
\hline \multirow[t]{2}{*}{ HL } & HL1 & $\begin{array}{l}\text { Walking regularly to identify the concepts of fractions in my } \\
\text { surroundings using U-Fraction app can strengthen my bones and } \\
\text { muscles. }\end{array}$ & 3.44 & 1.086 \\
\hline & HL2 & $\begin{array}{l}\text { Sensing the fresh air when I explore different fraction objects in my } \\
\text { surroundings using U-Fraction app makes me feel better. }\end{array}$ & 3.63 & .926 \\
\hline \multirow[t]{2}{*}{ CL } & CL1 & $\begin{array}{l}\text { I can enhance my knowledge in the discussion learning activity by } \\
\text { using U-Fraction app. }\end{array}$ & 4.11 & .974 \\
\hline & CL2 & $\begin{array}{l}\text { My peers can share their experiences and knowledge with me by } \\
\text { using U-Fraction app. }\end{array}$ & 3.89 & 1.188 \\
\hline \multirow[t]{2}{*}{$\mathrm{Cr}$} & $\mathrm{Cr} 1$ & $\begin{array}{l}\text { I can manipulate the fraction objects to solve the problems in U- } \\
\text { Fraction app. }\end{array}$ & 3.78 & 1.155 \\
\hline & $\mathrm{Cr} 2$ & $\begin{array}{l}\text { My imagination of fraction objects can be realized by solving the } \\
\text { problems in U-Fraction app. }\end{array}$ & 3.70 & 1.203 \\
\hline \multirow[t]{2}{*}{$\mathrm{Su}$} & Su1 & $\begin{array}{l}\text { Applying the concepts of fractions in my surroundings can motivate } \\
\text { me to learn more. }\end{array}$ & 3.89 & .974 \\
\hline & $\mathrm{Su} 2$ & $\begin{array}{l}\text { Using U-Fraction app to solve fraction problems in my surroundings } \\
\text { can help me to remember related previous knowledge. }\end{array}$ & 3.70 & 1.031 \\
\hline \multirow[t]{3}{*}{$\mathrm{Sc}$} & Sc1 & $\begin{array}{l}\text { I will suggest others to use U-Fraction app to explore fraction } \\
\text { objects in their surroundings. }\end{array}$ & 3.85 & 1.099 \\
\hline & $\mathrm{Sc} 2$ & $\begin{array}{l}\text { I will do more tasks in U-Fraction app to improve my understanding } \\
\text { of fraction concepts in my surroundings. }\end{array}$ & 3.70 & 1.031 \\
\hline & $\mathrm{Sc} 3$ & $\begin{array}{l}\text { I will do more tasks in U-Fraction app to get familiar with fraction } \\
\text { objects in my surroundings. }\end{array}$ & 3.85 & 1.167 \\
\hline
\end{tabular}

The results from the interview toward the features of U-Fraction and the learning activities are analyzed. Most students liked the annotation feature because it can help them to understand what they have learned about fractions. In the learning activities, they liked to do peer assessment because the scaffoldings that provide in the app can help them to make judgments. The following quotes are their perspectives toward the annotation feature and peer assessment activity.

Annotation feature.

- "It let us remember what we did", "it is important because the notes are helpful to review", "it is important, because if you only have pictures, you won't understand them".

- Peer assessment activity.

- "Because the scaffolding can help me whether another student assignment is drawn correctly or not", "I can learn how to grade others, and you can know whether the answer is right or wrong", "I can give judgment correct or wrong". 


\section{Discussion}

The analysis of knowledge acquisition indicates that the use of U-Fraction and authentic contexts could be beneficial to improve students' acquisition of fractions knowledge. This result was in harmony with previous studies, which mentioned that the use of the ubiquitous app and authentic contexts could improve students' learning achievements (Hwang et al. 2019b).

On the other hand, the results from correlation analysis imply that annotations that had been made by students were useful to understand the fraction concepts and improve their knowledge. Furthermore, by comparing the correlation results among quantity of tasks, quality of learning, and learning achievement, it indicated that students' learning achievement would more depend on their quality of learning rather than their quantity of tasks that had been solved by them.

Results from LSA indicate that students tend to do the next activity after they finished the previous activity. It is interesting to note that the learning activity in authentic contexts using the U-Fraction is significant in the forward sequences, although students can make backward steps. This implies that students, implementing fractions in authentic contexts, have a motivation to solve the existing fraction problem, which was found in a particular location. After they finished the previous problem, they will choose the other problem and have the intention to solve it. However, the behavior transition model, which explains in the result, is not the only possible model. This can depend on the types of tasks, the times while solving the tasks, and the design of tools that were used (Pohl et al. 2016).

Results from questionnaire analysis imply that students have confidence that fraction learning in authentic contexts using U-Fraction App can facilitate their collaborative learning, e.g., doing discussion and sharing knowledge. Moreover, learning by applying in authentic contexts almost reach 4, which means it can be the second variable as in consideration to improve students' positive perception toward their learning in authentic contexts. Such findings can be explained by the experience while students engaged in authentic activities to apply their fraction knowledge. Students not only sit on their chairs and study in the classroom. They explore their surroundings and making multiple representations to apply their knowledge in real applications. These learning experiences could give pleasant and fascinating activities in mathematics learning.

\section{Limitation and Conclusion}

Considering the potential benefits of authentic learning, this study implementing the authentic learning design supported by U-Fraction in order to give students more meaningful and interesting learning activities. The results indicate that authentic activities supported by U-Fraction could improve students' knowledge acquisition and the quality of learning engagement. Furthermore, sharing knowledge and assessing peer's task gives students a valuable experience to deal with others' opinions or new information that can improve their knowledge and understanding. Nevertheless, the study results should be interpreted in light of limitations. First, finding an appropriate authentic context in surroundings may be consumed amount of times which depend on the types of tasks. Thus, research findings may not be generalized to the other learning subject.

On the other hand, students' perceptions toward the activities in authentic learning supported by U-Fraction also investigated using SSAL Questionnaire possessing six variables, i.e., learning by applying (LA), healthy learning (HL), collaborative learning (CL), creativity (Cr), sustainability (Su) and Scalability (Sc). According to the results, it can be concluded that students have a high positive perception toward their learning, which is the learning has potentially given the experience to collaborate with others (CL) and apply their knowledge in authentic contexts (LA). However, this study examined the potential of collaboration and learning by applying in authentic contexts based on descriptive statistics. Future studies need to elaborate such findings with more empirical evidence by investigating the relationship among the dimension in SSAL 


\section{References}

Bakeman, R., and Gottman, J.M. (1997). Observing Interaction: An Introduction to Sequential Analysis (2nd ed.). Cambridge: Cambridge University Press.

Belk, M., Fidas, C., Germanakos, P., and Samaras, G. (2017, November). The interplay between humans, technology and user authentication: A cognitive processing perspective. Computers in Human Behavior, 76, 184-200. doi: 10.1016/j.chb.2017.06.042

Boticki, I., Wong, L.H., and Looi, C. (2013). Designing Technology for Content-Independent Collaborative Mobile Learning. IEEE Transaction on Learning Technology, 6(1), pp. 14-24. doi: 10.1109/TLT.2012.8

Brizuela, B. M. (2006). Young children's notations for fractions. Educational Studies in Mathematics, 2006, 62, 281-305. doi: 10.1007/s10649-005-9003-3

Chung, G. K., and Baker, E. L. (2003). An Exploratory Study to Examine the Feasibility of Measuring ProblemSolving Processes Using a Click-Through Interface. The Journal of Technology, Learning and Assessment, 2(2). Retrieved from https://ejournals.bc.edu/index.php/jtla/article/view/1662

DeBellis, V. A., \& Goldin, G. A. (2006). Affect and Meta-Affect in Mathematical Problem Solving: A Representational Perspective. Educational Studies in Mathematics, 63(2), 131-147. doi: 10.1007/s10649-0069026-4

Fornell, C., and Larcker, D.F. (1981). Structural Equation Models with Unobservable Variables and Measurement Error: Algebra and Statistics. Journal of Marketing Research, 18(3), 382-388. doi: $10.2307 / 3150980$

Hair, J. F., Sarstedt, M., and Ringle, C. M. (2019). Rethinking some of the rethinking of partial least squares. European Journal of Marketing, 53(4), 566-584. doi: 10.1108/EJM-10-2018-0665

Herrington, J., and Oliver, R. (2000). An instructional design framework for authentic learning environments. Educational Technology Research and Development, 48(3), 23-48. doi: 10.1007/BF02319856

Herrington, J., Reeves, T.C., and Oliver, R. (2014). Authentic learning environments. In Spector J., Merrill M., Elen J., Bishop M. (Eds), Handbook of research on educational communications and technology (pp. 401-412). New York: Springer. doi: 10.1007/978-1-4614-3185-5_32

Hwang, W. -Y., Purba, S.W.D., Liu, Y., Zhang, Y., and Chen, N. (2019a). An Investigation of the Effects of Measuring Authentic Contexts on Geometry Learning Achievement. IEEE Transaction on Learning Technology, 12(3), 291-302. doi: 10.1109/TLT.2018.2853750

Hwang, W. -Y., Shadiev, R., Tseng, C. -W., and Huang, Y. -M. (2015). Exploring effects of multi-touch tabletop on collaborative fraction learning and the relationship of learning behavior and interaction with learning achievement. Journal of Educational Technology \& Society, 18(4), 459-473

Hwang, W. -Y., Utami, I. Q., Purba, S. W. D., and Chen, H. S. L. (2019b). Effect of Ubiquitous Fraction App on Mathematics Learning Achievements and Learning Behaviors of Taiwanese Students in Authentic Contexts', IEEE Transaction on Learning Technology, 1-1. doi: 10.1109/TLT.2019.2930045

Jordan, N. C., Resnick, I., Rodrigues, J., Hansen, N., and Dyson, N. (2017). Delaware longitudinal study of fraction learning: Implications for helping children with mathematics difficulties. Journal of Learning Disabilities, 50(6), 621-630. doi: 10.1177/0022219416662033

Kara, F., \& Incikabi, L. (2018). Sixth Grade Students' Skills of Using Multiple Representations in Addition and Subtraction Operations in Fractions. International Electronic Journal of Elementary Education, 10(4), 463-474. Retrieved from https://www.iejee.com/index.php/IEJEE/article/view/462

Kong, S. C., and Kwok, L. F. (2003). A graphical partitioning model for learning common fraction: designing affordances on a web-supported learning environment. Computers \& Education, 40(2), 137-155. doi: 10.1016/S0360-1315(02)00118-5

Kukulska-Hulme, A., and Viberg, O. (2018). Mobile collaborative language learning: State of the art. British Journal of Education Technology, 49(2), 207-218. doi: 10.1111/bjet.12580

Nakahara, T. (2008). Cultivating Mathematical Thinking through Representation: Utilizing the Representational System. $\quad$ Retrieved from http://www.criced.tsukuba.ac.jp/math/apec/apec2008/papers/PDF/1.Keynote(Dec.9)_Tadao_Nakahara_Japan.pd $\mathrm{f}$ 
Newmann, F.M., and Wehlage, G.G. (1993). Five standards of authentic instruction. Educational Leadership, 50(7), 8-12.

Pohl, M., Smuc, M., and Mayr, E. (2012). The user puzzle-explaining the interaction with visual analytics systems. IEEE Transactions on Visualization and Computer Graphics, 18(12), 2908-2916. doi: 10.1109/TVCG.2012.273

Pohl, M., Wallner, G., and Kriglstein, S. (2016, December). Using lag-sequential analysis for understanding interaction sequences in visualizations. International Journal of Human-Computer Studies, 96, 54-66. doi: 10.1016/j.ijhcs.2016.07.006

Radinsky, K., Svore, K. M., Dumais, S. T., Shokouhi, M., Teevan, J., Bocharov, A., and Horvitz, E. (2013). Behavioral dynamics on the web: Learning, modeling, and prediction. ACM Transactions on Information Systems, 31(3), 1-37. doi: 10.1145/2493175.2493181

Reychav, I., and Wu, D. (2016, September). The interplay between cognitive task complexity and user interaction in mobile collaborative training. Computers in Human Behavior, 62, 333-345. doi: 10.1016/j.chb.2016.04.007

Spiro, R. J., Feltovich, P. J., Jacobson, M. J., \& Coulson, R. L. (1992). Cognitive flexibility, constructivism, and hypertext: Random access instruction for advanced knowledge acquisition in ill-structured domains. In T. M. Duffy, \& D. H. Jonassen, (Eds.), Constructivism and the technology of instruction: A conversation, (pp. 57-75). Lawrence Erlbaum Associates, Inc.

Shadiev, R., Hwang, W.Y., Huang, Y.M., and Liu, T.Y. (2018). Facilitating application of language skills in authentic environments with a mobile learning system. Journal of Computer Assisted Learning, 34(1), 42-52. doi: $10.1111 /$ jcal. 12212

Wadsworth, B. J. (1996). Piaget's theory of cognitive and affective development: Foundations of constructivism. New York: Longman Publishing.

Wang, C., Fang, T., and Gu, Y. (2020, January). Learning performance and behavioral patterns of online collaborative learning: Impact of cognitive load and affordances of different multimedia. Computers \& Education, 143, 103683. doi: 10.1016/j.compedu.2019.103683

Wu, S. -Y., Chen, S. Y., and Hou, H. -T. (2016). Exploring the interactive patterns of concept map-based online discussion: a sequential analysis of users' operations, cognitive processing, and knowledge construction. Interactive Learning Environments, 24(8), 1778-1794. doi: 10.1080/10494820.2015.1057740

Van Gog, T., Kester, L., and Paas, F. (2011). Effects of concurrent monitoring on cognitive load and performance as a function of task complexity. Applied Cognitive Psychology, 25(4), 584-587. doi: 10.1002/acp. 1726

Volk, M., Cotič, M., Zajc, M., and Starcic, A.I. (2017, November). Tablet-based cross-curricular maths vs. traditional maths classroom practice for higher-order learning outcomes. Computers \& Education, 114, 1-23. doi: 10.1016/j.compedu.2017.06.004 
Appendix

Pre-test

\section{PRETEST}

Name :

Students number :

\section{Understanding Fractions}

1. Which rectangle is not divided into four equal parts?

A.

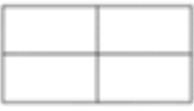

C.

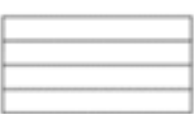

B.

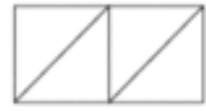

D.

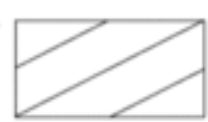

2. Which shows $\frac{3}{4}$ of the picture shaded?

A.

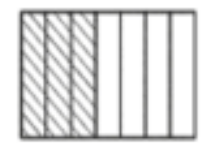

C.

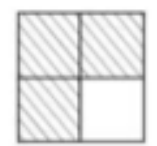

B

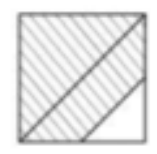

D

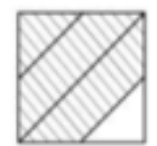

3. Look at the shaded parts. Add the fractions in the circles.

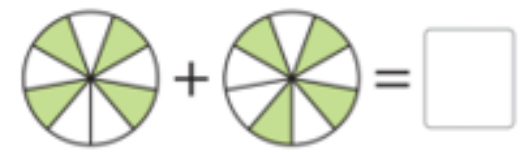

Visualize, Estimate and Create Representations of Fractions

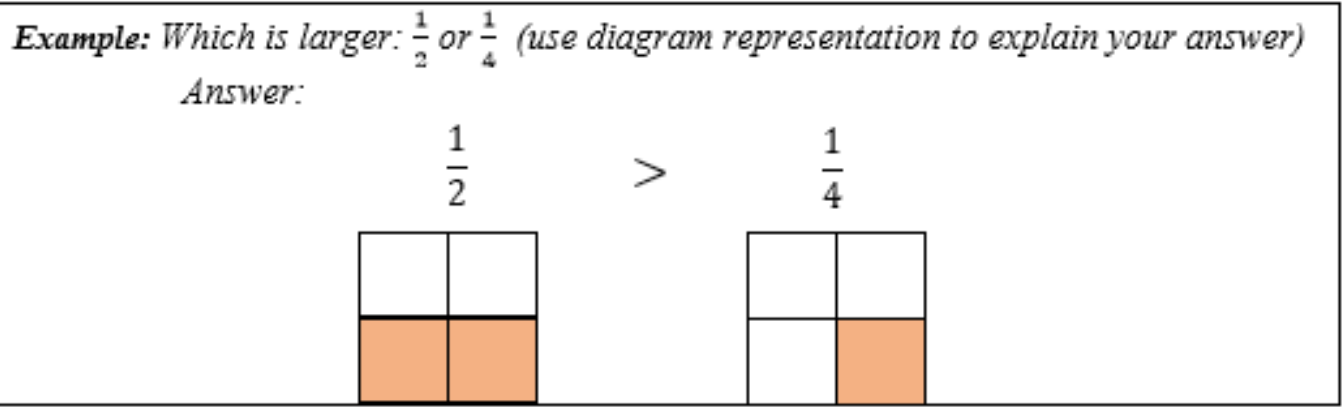

4. Which is larger: $\frac{1}{3}$ or $\frac{1}{5}$ (use diagram representation to explain your answer) 
5. Which is greater than one: $\left(\frac{1}{3}+\frac{2}{4}\right)$ or $\left(\frac{2}{3}+\frac{2}{5}\right)$ (use diagram representation to explain your answer)

6. Which is larger: $\left(\frac{1}{3}-\frac{1}{4}\right)$ or $\left(\frac{2}{3}-\frac{1}{2}\right)$ (use diagram representation to explain your answer)

\section{Problem Solving}

7. A book has 8 chapters of equal length. You have read 4 chapters. What fraction of the book do you have left to read?

8. A log is divided into 3 parts, all the same size. What fraction of the log is each log hold? 


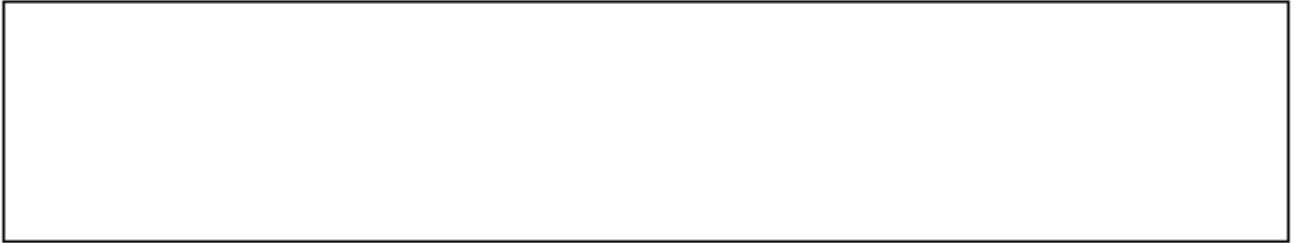

9. One-half of wall is painted red. The other half is divided into three equal parts painting with blue, yellow, and green. What fraction of the wall is painted yellow?
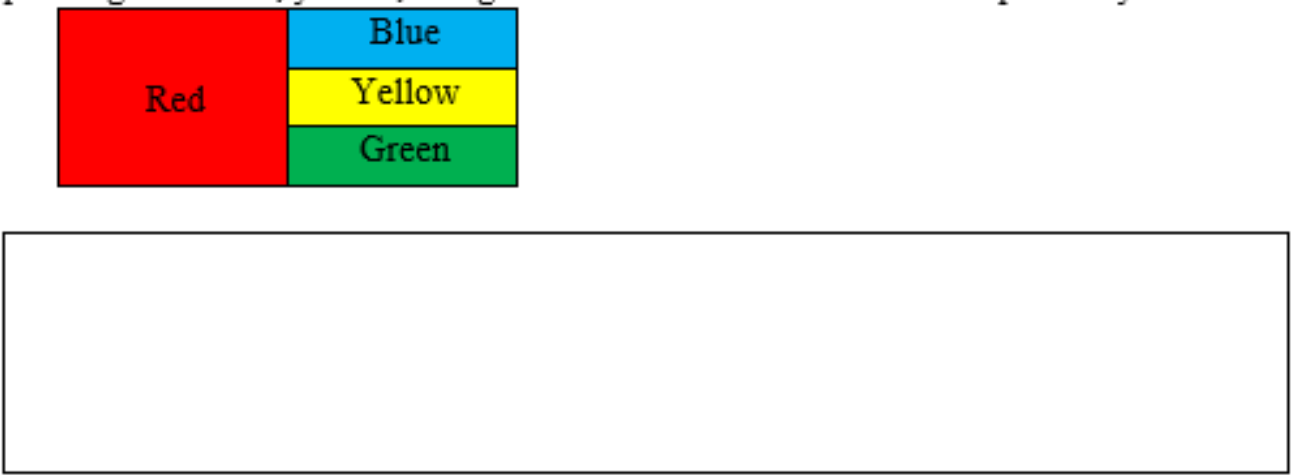

10. A sausage has been sliced into 28 slices of the same size. How many slices would equal $\frac{3}{7}$ of the sausages. Use picture to demonstrate your answer. 